\title{
3-dimensional Analysis of Regenerative Endodontic Treatment Outcome
}

\author{
Mostafa EzEldeen, DDS, MScD, ${ }^{* \dagger}$ Gertrude Van Gorp, DDS, MScD ${ }^{\dagger}$ Jeroen Van Dessel, MSc, * \\ Dirk Vandermeulen, PhD, ${ }^{\neq}$and Reinbilde Jacobs, DDS, PhD, MSc, Dr bc *
}

\section{Ahstract}

Introduction: A growing body of evidence supports the regeneration potential of dental tissues after regenerative endodontic treatment (RET). Nevertheless, a standard method for the evaluation of RET outcome is lacking. The aim of this study was to develop a standardized quantitative method for RET outcome analysis based on cone-beam computed tomographic (CBCT) volumetric measurements. Methods: Five human teeth embedded in mandibular bone samples were scanned using both an Accuitomo 170 CBCT machine (Morita, Kyoto, Japan) and a SkyScan 1174 micro-computed tomographic $(\mu \mathrm{CT})$ system (SkyScan, Antwerp, Belgium). For subsequent clinical application, clinical data and low-dose CBCT scans (preoperatively and follow-up) from 5 immature permanent teeth treated with RET were retrieved. In vitro and clinical 3-dimensional image data sets were imported into a dedicated software tool. Two segmentation steps were applied to extract the teeth of interest from the surrounding tissue (livewire) and to separate tooth hard tissue and root canal space (level set methods). In vitro and clinical volumetric measurements were assessed separately for differences using Wilcoxon matched pairs test. Pearson correlation analysis and Bland-Altman plots were used to evaluate the relation and agreement between the segmented CBCT and $\mu \mathrm{CT}$ volumes. Results: The results showed no statistical differences and strong agreement between $\mathrm{CBCT}$ and $\mu \mathrm{CT}$ volumetric measurements. Volumetric comparison of the root hard tissue showed significant hard tissue formation. (The mean volume of newly formed hard tissue was 27.9 $\left.[ \pm 10.5] \mathrm{mm}^{3}[P<.05]\right)$. Conclusions: Analysis of 3-dimensional data for teeth treated with RET offers valuable insights into the treatment outcome and patterns of hard tissue formation. (J Endod 2015; $\square: 1-8$ )

\section{Key Words}

Cone-beam computed tomographic imaging, MeVislab, regenerative endodontic treatment, teeth segmentation

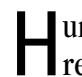
umans, unlike species such as salamander or newt, lack the ability to naturally regenerate their own tissues. To overcome this limitation, tissue engineering strategies using combinations of biocompatible scaffolds, growth factors, and stem cells to mimic natural morphogenesis are currently in development (1). Among those strategies are regenerative endodontic procedures, which can be defined as biologically based processes designed to replace damaged structures, including dentin and root structures, as well as cells of the pulp-dentin complex (2).

The potential for dental tissue regeneration and continued root development is well documented in studies of replanted and autotransplanted teeth (3-5). There is a growing body of evidence from case reports to suggest that regenerative endodontics may in fact be possible in teeth with pulpal necrosis, apical pathosis, and immature apices (6-9). This treatment procedure has acquired many names such as pulp revitalization, root canal revascularization, and regenerative endodontic treatment (RET) (2, 9-11). The outcomes of these case reports have been evaluated clinically and radiographically in 2 dimensions. The most frequent pretreatment diagnosis of these cases was of pulpal necrosis with or without apical periodontitis. Postoperative recalls showed regression of clinical symptoms in addition to radiographic evidence of hard tissue formation and apical closure $(6-10,12)$. However, the application of nonstandardized 2-dimensional (2D) radiographs to evaluate an increase in root length and dentin thickness should be interpreted with caution because a slight change in the angulation at the preoperative or recall appointment might produce inconsistent images and inaccurate interpretations (12).

Taking into consideration the limitations of 2D imaging, 3-dimensional (3D) imaging using cone-beam computed tomographic (CBCT) imaging has proven itself as a valuable tool in dentistry (13-15) as long as radiation doses are controlled at reasonably low levels (16). Moreover, volumetric measurements from CBCT data have been reported and validated in several studies in vitro and in vivo (13-15, 17-20). The overall aim of this study was to develop a standardized quantitative method for the evaluation and analysis of the outcome of RET based on CBCT volumetric measurements.

From the *OIC, OMFS IMPATH Research Group, Faculty of Medicine, Department of Imaging and Pathology, KU Leuven and Oral and Maxillofacial Surgery, University Hospitals Leuven, Leuven, Belgium; ${ }^{\dagger}$ Department of Oral Health Sciences, KU Leuven and Paediatric Dentistry and Special Dental Care, University Hospitals Leuven, Leuven, Belgium; and ${ }^{\ddagger}$ Medical Image Computing, ESAT/PSI, Department of Electrical Engineering, KU Leuven, Leuven, Belgium.

Address requests for reprints to Dr Mostafa EzEldeen, OIC, OMFS IMPATH Research Group, Faculty of Medicine, Department of Imaging and Pathology, KU Leuven and Oral and Maxillofacial Surgery, University Hospitals Leuven, Kapucijnenvoer 33, 3000 Leuven, Belgium. E-mail address: mostafa.ezeldeen@uzleuven.be 0099-2399/\$ - see front matter

Copyright (C) 2015 American Association of Endodontists. http://dx.doi.org/10.1016/j.joen.2014.10.023 


\section{Materials and Methods \\ In Vitro Validation [CBCT Imaging Versus Micro-computed Tomographic Imaging]}

Image Acquisition and Export. Five human teeth in bone samples from the left and right mandible (1 incisor, 2 canines, 1 singlerooted premolar, and 1 molar) were scanned using a high-resolution CBCT machine $(80 \mu \mathrm{m})$ (3D Accuitomo 170; Morita, Kyoto, Japan). Each sample was placed in a sponge block to prevent any movement during the scanning process. Scanning parameters were fixed at $360^{\circ}$ rotation, 30.8-second exposure time, $80-\mu \mathrm{m}$ voxel size, high resolution, and a field of view of $60 \times 60 \mathrm{~mm}$. Images were acquired under the exposure condition of $90.0 \mathrm{kV}$ (x-ray tube voltage) and $5.0 \mathrm{~mA}$ (x-ray tube electric current). All data sets were exported using the Digital Imaging and Communications in Medicine (DICOM) file format with an isotropic voxel size of $80 \mu \mathrm{m}$, a slice interval and thickness of $80 \mu \mathrm{m}$ and $160 \mu \mathrm{m}$, and a slice interval and thickness of $160 \mu \mathrm{m}$.

The samples were subsequently scanned with the SkyScan 1174 micro-computed tomographic ( $\mu \mathrm{CT}$ ) system (SkyScan, Antwerp, Belgium). The $\mu \mathrm{CT}$ parameters were $30-\mu \mathrm{m}$ voxel size, $50 \mathrm{kVp}$, $800 \mathrm{~mA}, 1-\mathrm{mm}$ aluminum filter, angular rotation step of $0.8^{\circ}, 360^{\circ}$ scanning, 450 projections, and an exposure time of 5 seconds with a total scan duration of 1 hour 31.6 minutes. All data sets were imported using the DICOM file format with a voxel size of $30 \mu \mathrm{m}$.

\section{Clinical Application.}

Study Sample. This case series included 5 immature permanent teeth with infected necrotic pulps and apical periodontitis/abscess from 4 patients who attended the Pediatric Dental Clinic of the University Hospital of the KU Leuven, Leuven, Belgium. Table 1 presents the demographic details of the subjects, signs and/or symptoms, and pulpal and periapical status of involved teeth. The age of the patients ranged in age from 9.9-14.8 years at the start of treatment. The patients presented with dental trauma (1 maxillary incisor), dens evaginatus (3 maxillary incisors), and pulp necrosis after autotransplantation (1 premolar). Radiographically, all teeth showed evidence of periapical lesions caused by root canal infection; 1 tooth showed early signs of external cervical root resorption (premolar). All teeth had an immature apex, either blunderbuss or in the form of a wide canal with parallel walls and an open apex. After clinical and radiographic examination, a vitality pulp test was performed on the affected tooth and a control (contralateral but unaffected) tooth. The patients and their parents were informed of the treatment plan (for RET) and the potential risks before giving their consent to the treatment.

\section{RET Technique}

All teeth were anesthetized using mepivacaine 3\% without epinephrine (Scandonest; Septodont, Saint Maur des Fosses, France) to avoid compromising the blood supply and then isolated with a rubber dam. The access cavity was prepared with a \#2 high-speed access bur (round-end cutting tapered diamond bur) (Maillefer, Dentsply, Switzerland) and copious water spray. The canals were gently rinsed with sodium hypochlorite ( $\mathrm{NaOCl}$ ) $2.5 \%$ solution without instrumenta- tion. The canal was then dried by aspiration (without air blow) and application of sterile paper points (Henry Schein, Melville, NY). A biantibiotic mixture of ciprofloxacin and metronidazole was placed in the root canal and left for 10-14 days. The access cavity was sealed with resin-modified glass ionomer cement (Fuji VII; GC, Tokyo, Japan). In the next visit, under an endodontic microscope, the root canal was re-entered and irrigated with a copious amount of $2.5 \% \mathrm{NaOCl}$ to remove the antibiotic dressing material and all debris. The root canal dentin was conditioned using EDTA 17\% (21). The canal was then dried with sterile paper points and was confirmed to have no exudate. A size \#10 K-file was introduced into the root canal until vital tissue was felt, and this instrument was used to irritate the tissue to create some bleeding into the root canal (Fig. 1A). The bleeding was allowed to reach a level of 3-4 $\mathrm{mm}$ below the cementoenamel junction (Fig. $1 B$ ). Then, an absorbable collagen barrier (CollaPlug; Zimmer Dental, Carlsbad, CA) was placed to create a barrier to apply a dense layer of $4 \mathrm{~mm}$ white mineral trioxide aggregate (ProRoot MTA; Dentsply Tulsa Dental Products, Tulsa, OK) until the cementoenamel junction (Fig. 1C-E). The tooth was then temporarily sealed using a moist sterile paper point to provide the water needed for mineral trioxide aggregate to fully set and resin-modified glass ionomer cement (Fuji VII). After 714 days, the temporary filling and moist paper point were removed, and the hardness of mineral trioxide aggregate was inspected. The final coronal seal was established using adhesive composite restoration, and the patient was scheduled for a recall appointment (Fig. $1 F-J)$.

Image Acquisition and Export. СBCT images were obtained based on clinical justification by the treating endodontist as part of the treatment protocol (preoperatively and at $>12$ months follow-up) because of the severity of the lesions and in the framework of the insurance case follow-up. Images were obtained with the Accuitomo 170 using an $80 \times 80 \mathrm{~mm}$ field of view. Images were acquired under the exposure condition of $90.0 \mathrm{kV}$ (x-ray tube voltage) and $5.0 \mathrm{~mA}$ (x-ray tube electric current). The exposure time was 17.5 seconds. All data sets were exported using the DICOM file format with a voxel size of $160 \mu \mathrm{m}$ and a slice interval of $160 \mu \mathrm{m}$ (1 voxel).

Segmentation Strategy. All scanned samples (CBCT and $\mu \mathrm{CT}$ ) and full CBCT scans (case series study) were imported into MeVisLab (MeVis Research, Bremen, Germany), a highly developed free framework system that provides an easy-to-learn modular visual programming interface with a comprehensive suite of image processing and visualization tools (http://www.mevislab.de/). For the clinical data, the region of interest including the tooth treated with RET (pre- and postoperative) and the contralateral negative control tooth were saved as a new image in DICOM format to reduce computation time. All region of interest images were normalized using an intensity windowing filter and then a median filter to suppress any noise and decrease confounding variables between the images.

Two segmentation steps were applied to extract the teeth of interest from the surrounding tissue (bone) and to separate tooth hard tissue (enamel and dentine) and root canal space. The first step is a dedicated tool developed in MeVisLab that applies interactive livewire boundary extraction to extract the tooth of interest from the surrounding tissue.

TABLE 1. Demographic Details of the Subjects, Signs and/or Symptoms, and Pulpal and Periapical Status of Involved Teeth

\begin{tabular}{lrcllcc}
\hline Case number & Age & Sex & \multicolumn{1}{c}{ Tooth number } & Signs/symptoms & Pulpal status & Periapical lesion \\
\hline 1 & 9.9 & F & Maxillary right central incisor & Swelling and pain & Necrosis & + \\
2 & 8.9 & F & Maxillary right central incisor & Swelling and pain & Necrosis & + \\
3 & 14.8 & F & Mandibular right first premolar & No & Necrosis & + \\
4 & 11.8 & F & Maxillary right lateral incisor & Swelling and pain & Necrosis & + \\
5 & 12.2 & F & Maxillary left lateral incisor & Swelling and pain & Necrosis & + \\
\hline
\end{tabular}



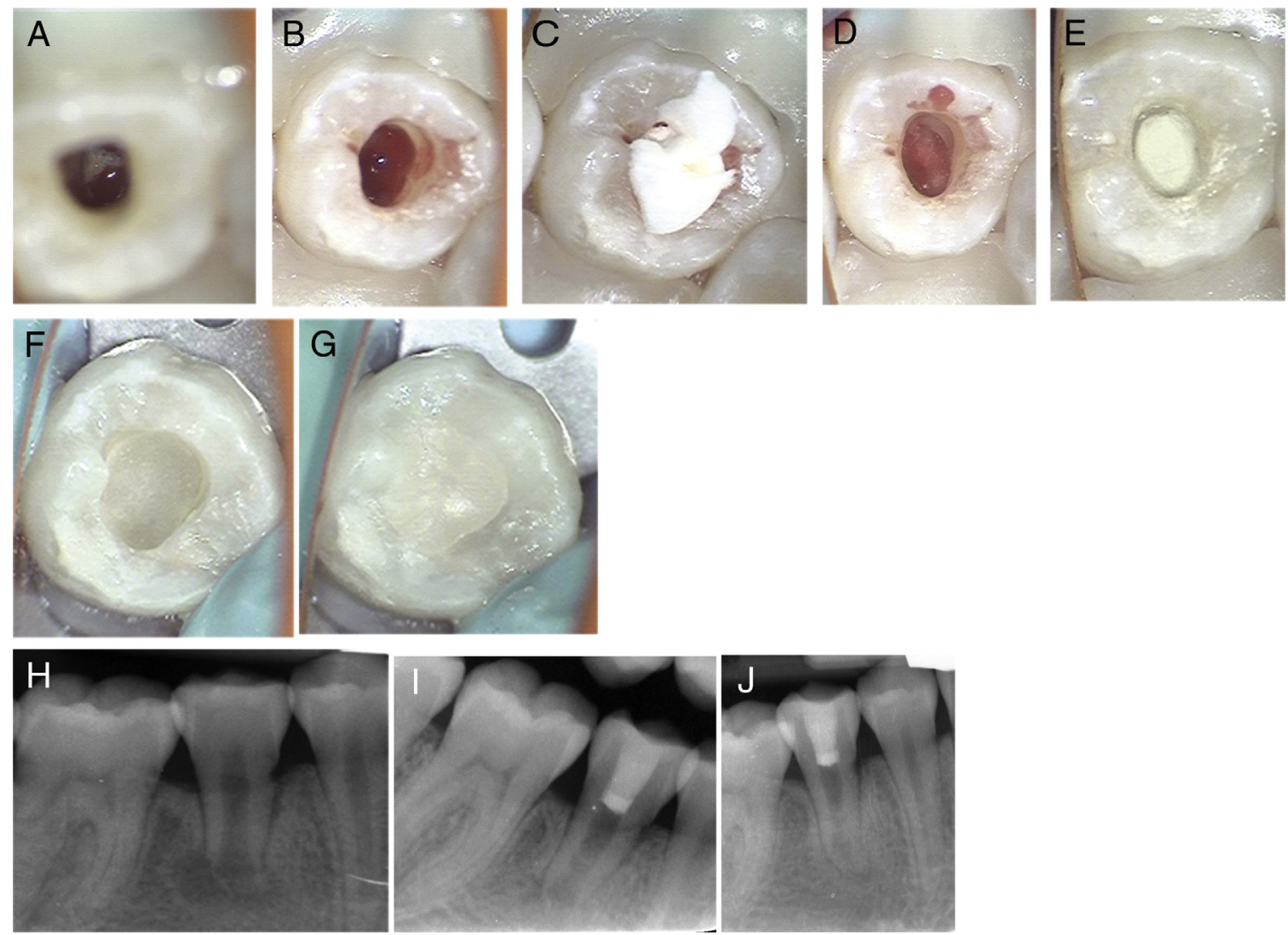

Figure 1. RET procedure: $(A$ and $B)$ the induction of bleeding inside the canal, $(C$ and $D)$ the placement of the CollaPlug to act as a barrier for MTA condensation, and $(E)$ MTA placement. ( $F$ and $G$ ) At the second visit, the hardness of MTA is controlled, and the coronal seal is established using glass ionomer and adhesive composite resin. (H) A preoperative radiograph. (I) A periapical radiograph directly after the second visit. $(J)$ A periapical radiograph 3 months after RET.

Livewire allows for a semi-interactive segmentation of structures with prominent edge image features. Internally, the module generates a graph representation of the image to work on; the graph's nodes represent image pixels, and edges connect neighboring pixels. The edges are weighted on the basis of the cost function (image gradient magnitude). If starting and ending points are defined on such a graph, the shortest path (minimal cost path) is computed using dynamic programming (F* algorithm) (22, 23). The second step applies semiautomatic user-guided 3D active contour segmentation using level set methods $(23,24)$, available in the ITK-SNAP tool kit (www.itksnap.org) (24). In the first step, a probability map was computed by applying a 1-sided smooth threshold once for hard tissue and another for the root canal space. In the second step, segmentation was initialized by placing 1 or more spherical seeds in the region of interest (hard tissue or canal). The last step was specifying the weights of the various terms in the active contour evolution partial differential equation and running the evolution interactively (24).

\section{D Reconstruction and Quantitative Visualization of Hard Tissue Formation}

After segmentation, the 3D triangle-based surface of the hard tissue and the root canal was reconstructed without being smoothed to preserve its raw volume measurement. The volumes of the root hard tissue and root canal were calculated starting from the cementoenamel junction up to the apex pre- and postoperatively. Geometry quantification was performed in MeVisLab using the framework described by Gao et al (25). The root canal diameter (thickness) was measured and color coded, and then the root hard tissue thickness measurement (starting from the cementoenamel junction up to the apex) was expressed as a color-coded map showing the calculated minimal distances from the canal surface to the external root surface (25).

\section{Volumetric Comparison and Statistical Analysis}

All data were analyzed with statistical software package STATISTICA 8.0 (StatSoft Inc, Tulsa, OK). In the first step, the accuracy of the volume measurements using CBCT imaging was evaluated by comparing the segmented volumes for hard tissue and root canal of the same samples to the volume segmented from $\mu \mathrm{CT}$ scans using the Wilcoxon matched pairs test. Pearson correlation analysis was performed to examine the potential linear relationship between the segmented volumes (hard tissue and root canal separately) from CBCT and $\mu \mathrm{CT}$ imaging. The degree of agreement between the segmented volumes from CBCT and $\mu \mathrm{CT}$ imaging was compared using the method of Bland and Altman (26). In this method, the difference between the measurements is plotted against their mean because the mean is considered to be the best estimate of the true values. The volumetric changes after RET were tested by comparing the root hard tissue volume pre- and postoperatively starting from the cementoenamel junction up to the apex using the Wilcoxon matched pairs test.

\section{In Vitro Validation}

\section{Results}

Hard tissue and root canal segmented volumes for the samples were used to test the correlation between the $\mu \mathrm{CT}$ and CBCT volumes; 


\section{Clinical Research}

a strong correlation was found (hard tissue at $80 \mu \mathrm{m}$ and $160 \mu \mathrm{m}$ : $r=0.99, P<.0001$; root canal at $80 \mu \mathrm{m}$ and $160 \mu \mathrm{m}: r=0.99$, $P<.001)$. The comparison of the measurements of segmented volumes (hard tissue and root canal) from $\mu \mathrm{CT}$ and CBCT imaging

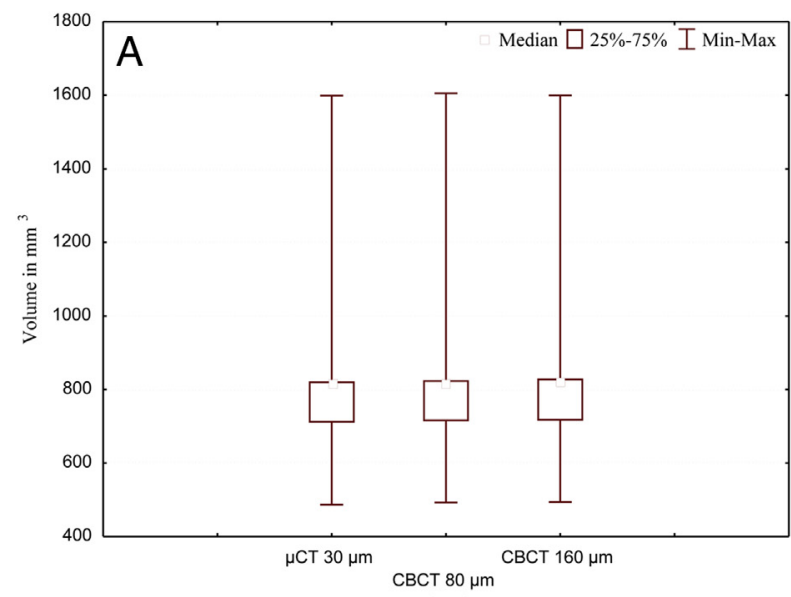

Hard tissue
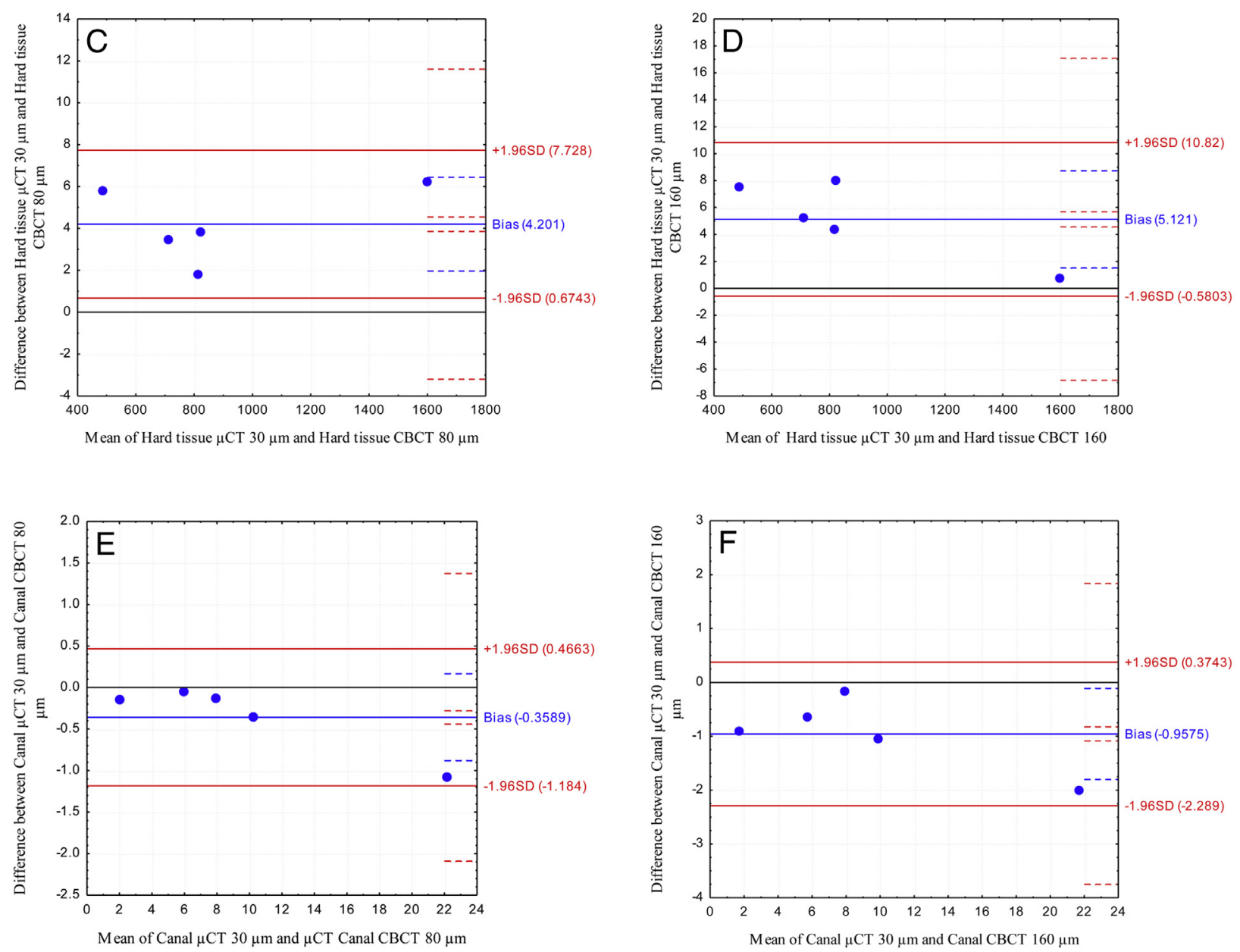

Figure 2. In vitro validation. (A) A box plot comparison between segmented volumes in $\mathrm{mm}^{3}$ (hard tissue) from $\mu \mathrm{CT}$ imaging at $30 \mu \mathrm{m}$ and CBCT imaging at $80 \mu \mathrm{m}$ and $160 \mu \mathrm{m}$. $(B)$ A box plot comparison between segmented volumes $\mathrm{mm}^{3}$ (root canal) from $\mu \mathrm{CT}$ imaging at $30 \mu \mathrm{m}$ and CBCT imaging at $80 \mu \mathrm{m}$ and $160 \mu \mathrm{m}$. $(C$ and $D)$ A Bland-Altman plot between the hard tissue segmented volumes from $\mu \mathrm{CT}$ imaging at $30 \mu \mathrm{m}$ and CBCT imaging at $80 \mu \mathrm{m}$ and $160 \mu \mathrm{m}$ (the difference between the measurements is plotted against their mean). ( $E$ and $F)$ A Bland-Altman plot between the root canal segmented volumes from $\mu \mathrm{CT}$ imaging at $30 \mu \mathrm{m}$ and CBCT imaging at $80 \mu \mathrm{m}$ and $160 \mu \mathrm{m}$ (the difference between the measurements is plotted against their mean). 
Clinical Research

TABLE 2. Summary of RET Outcome

\begin{tabular}{lccccc}
\hline Case number & $\begin{array}{c}\text { Follow-up } \\
\text { period (months) }\end{array}$ & $\begin{array}{c}\text { Healing of } \\
\text { periapical lesion }\end{array}$ & $\begin{array}{c}\text { Apical } \\
\text { obliteration }\end{array}$ & $\begin{array}{c}\text { Apical foramen diameter } \\
\text { before RET** }\end{array}$ (mm) & $\begin{array}{c}\text { Apical foramen diameter } \\
\text { after RET** }\end{array}$ \\
\hline 1 & 24 & Yes & Yes & 1.63 & 0.50 \\
2 & 16 & Yes & Yes & 2.02 & 0.0 \\
3 & 12 & Yes & Yes & 4.48 & 0.20 \\
4 & 25 & Yes & Yes & 3.84 & 0.3 \\
5 & 20 & Yes & Yes & 3.38 & 1.13 \\
\hline
\end{tabular}

RET, regenerative endodontic treatment.

*Measured in the axial view at the most apical part.

hard tissue and root canal volumes showed an agreement between the $\mu \mathrm{CT}$ and CBCT segmented volumes. The segmented hard tissue volumes from CBCT imaging at $80 \mu \mathrm{m}$ and $160 \mu \mathrm{m}$ were slightly bigger $\left(4.20 \mathrm{~mm}^{3}\right.$ and $\left.5.12 \mathrm{~mm}^{3}\right)$ than the segmented volume from $\mu \mathrm{CT}$ im- aging at $30 \mu \mathrm{m}$ (Fig. $2 C$ and $D$ ). Furthermore, the segmented root canal volumes from CBCT imaging at $80 \mu \mathrm{m}$ and $160 \mu \mathrm{m}$ were slightly smaller $\left(-0.35 \mathrm{~mm}^{3}\right.$ and $\left.-0.95 \mathrm{~mm}^{3}\right)$ than the segmented volume from $\mu \mathrm{CT}$ imaging at $30 \mu \mathrm{m}$ (Fig. $2 E$ and $F$ ).

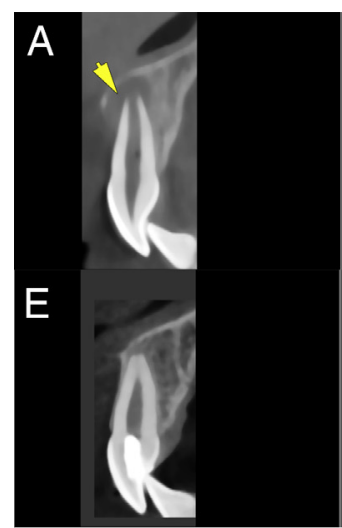

I
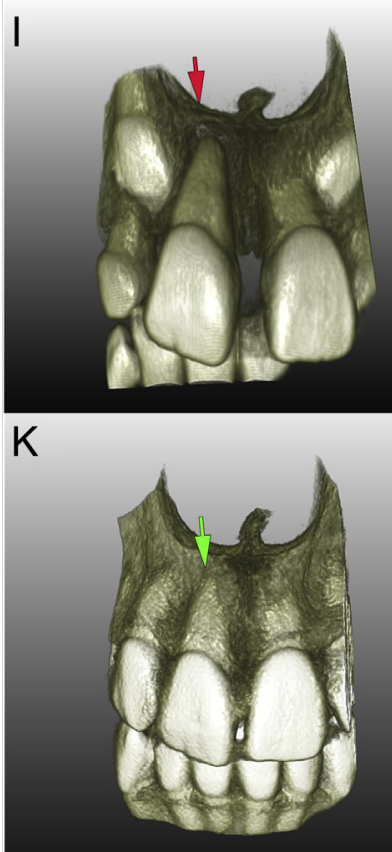
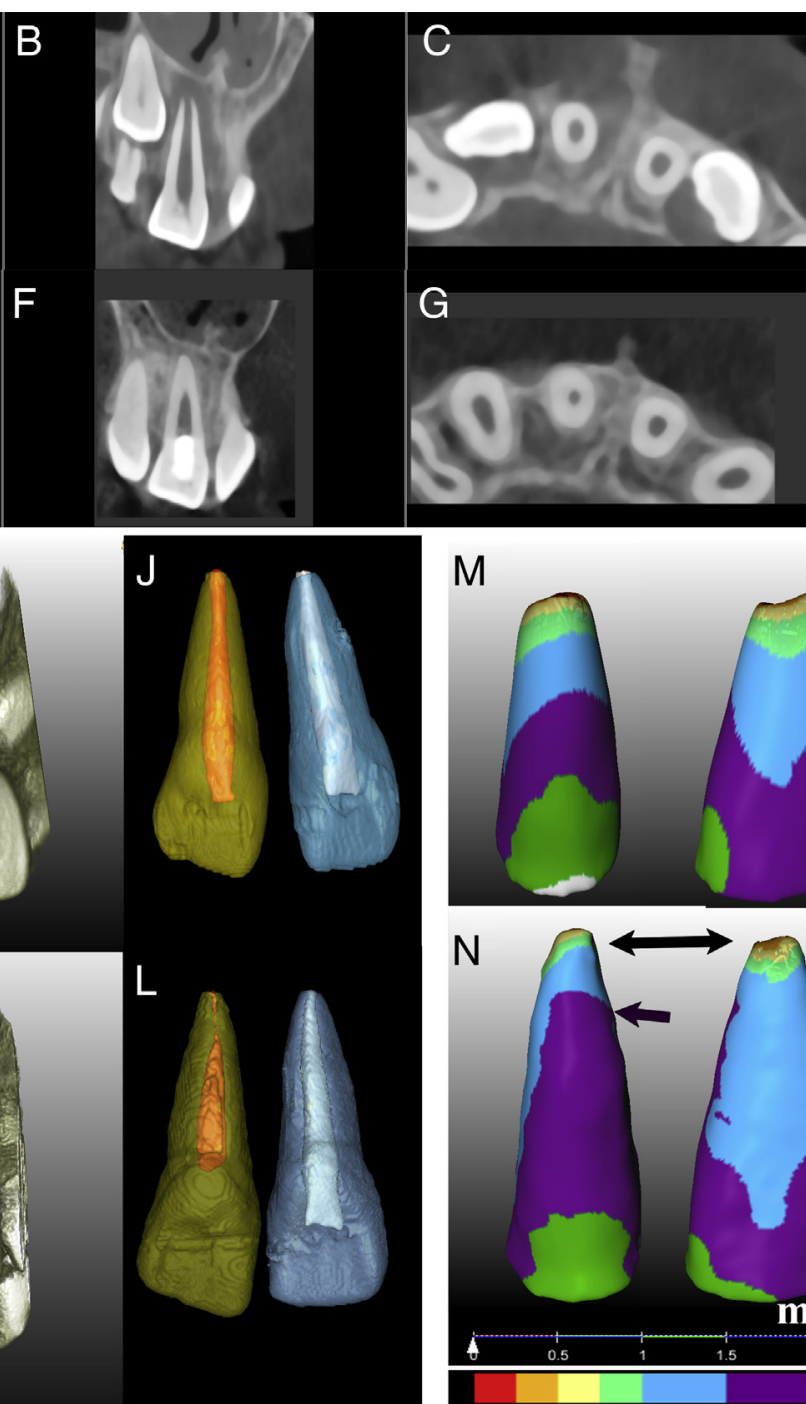

M

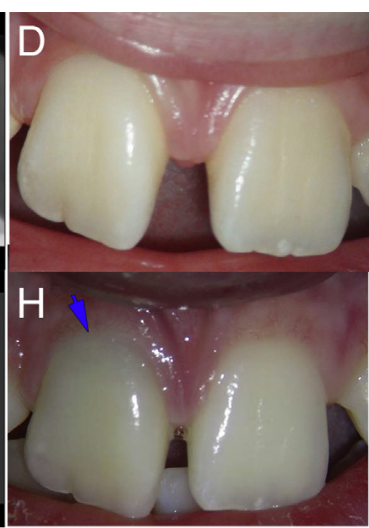

Before RET
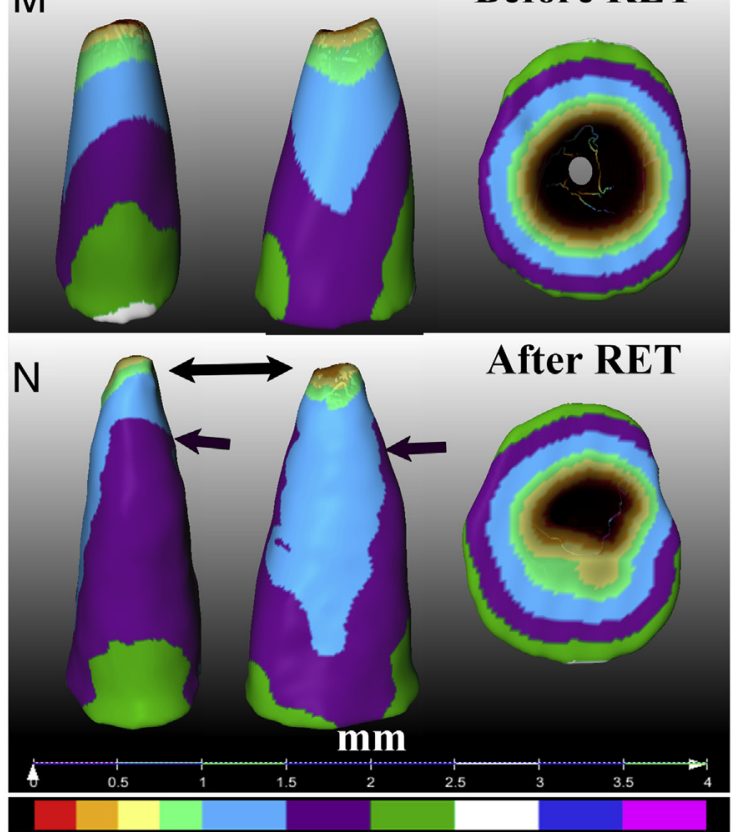

Figure 3. Case 1: a 9.9-year-old girl presented with pain related to dens evaginatus on the maxillary right central incisor. $(A-C)$ A CBCT scan showed an immature apex, periapical lesion, and excessive buccal bone loss (yellow arrow). $(D)$ A clinical picture before treatment. $(E-G)$ A coregistered CBCT scan 24 months after RET showing periapical and buccal bone healing and formation of hard tissue apically. $(H)$ A clinical picture 24 months after RET (note the gray discoloration in the cervical region caused by MTA) (blue arrow). (I) Three-dimensional reconstruction showing the extent of buccal bone loss (red arrow). (J) Three-dimensional segmentation for the maxillary right central incisor (yellow) and the contralateral tooth (blue). (K) Three-dimensional reconstruction 24 months after RET showing buccal bone healing (green arrow). ( $L$ ) Three-dimensional segmentation showing apical maturation after RET (note the progressive nature of apical hard tissue formation compared with the contralateral control). ( $M$ and $N$ ) Three-dimensional volumetric analysis of hard tissue changes after RET showing newly formed hard tissue apically (black arrow) and increased root thickness in the buccolingual dimension (purple color on the root surface and purple arrows). 


\section{Clinical Research}
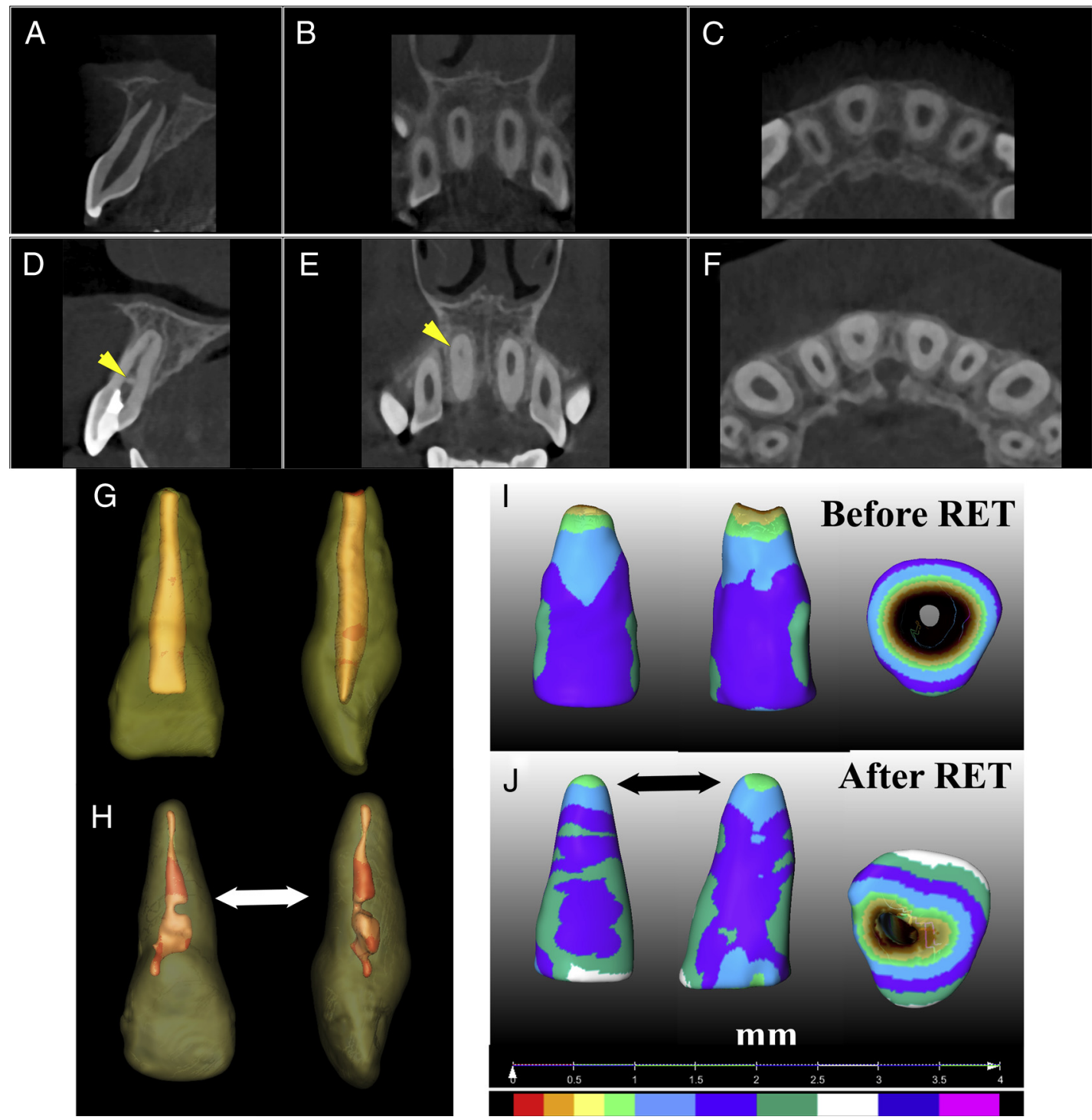

Before RET

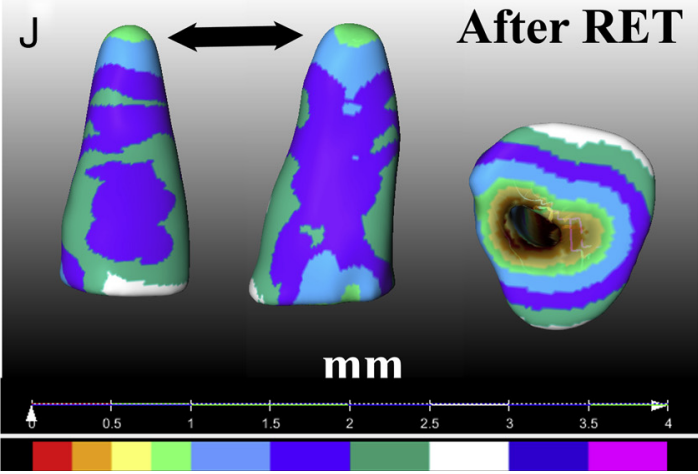

Figure 4. Case 2: an 8.9-year-old girl presented with pain and swelling related to the maxillary right central incisor (7 months after dental trauma in a car accident). (A-C) A CBCT scan showed an immature apex, periapical lesion, and bone loss related to the maxillary right central incisor. (D-F) A coregistered CBCT scan 16 months after RET showing healing of the periapical lesion and thickening of the root walls with root canal obliteration (yellow arrows). $(G)$ Threedimensional reconstruction before RET showing the size of root canal and rootdentin thickness. $(H)$ Three-dimensional reconstruction showing the nonuniform nature of hard tissue deposition on the canal walls and progressive root canal obliteration (white arrow). (I and $J$ ) Three-dimensional volumetric analysis of the root (sectioned from the cementoenamel junction showing nonuniform hard tissue gain after RET [purple and dark green color on root surface] and apical blunting [black arrow]).

\section{Clinical Application: RET Outcome}

Table 2 summarizes the results of RET. The mean follow-up period was $19.4( \pm 5.4)$ months. All subjects showed clinical evidence of resolution of signs and symptoms at follow-up visits related to the treated teeth. All teeth were free of any signs of soft tissue pathology; all teeth reacted normally to palpation and percussion tests and showed normal mobility. CBCT evaluation showed complete healing of periapical lesions with bone formation (Figs. $3 A-N$ and $4 A-J$ ). Table 3 summarizes the results of the 3D analysis; all teeth showed thickening of the root canal walls and continuing root maturation (apex formation). All teeth showed hard tissue formation on the internal walls of the root canal with 2 teeth showing progressive apical obliteration (Fig. $4 B$ and $D$ ). 3D volumetric comparison of the root hard tissue showed significant hard tissue formation $(P<.05)$; the mean volume of newly formed hard tissue was $27.9( \pm 10.5) \mathrm{mm}^{3}$ (Table 3$)$.

\section{Discussion}

This study reports a novel method for the evaluation and analysis of the RET outcome. The presented data confirm the accuracy of volumetric measurements from CBCT data compared with $\mu \mathrm{CT}$ data. Liu et al (17) reported a slight deviation of segmented teeth volumes from the physical volumes within $-4 \%$ to $7 \%$ using manual segmentation strategies and without any smoothing operations. Furthermore, Michetti et al (19) reported slightly smaller segmented root canal volumes from CBCT data (less than 3\%) compared with the volumes measured from digitized images from histologic sections.

The current study applied volumetric measurements from CBCT data obtained for pre- and post-RET to analyze treatment outcome in a standardized quantitative method. All teeth included in the current study showed hard tissue volume gain demonstrating the success of 
TABLE 3. A Summary of 3-dimensional Analysis

\begin{tabular}{lcccc}
\hline $\begin{array}{c}\text { Case } \\
\text { number }\end{array}$ & $\begin{array}{c}\text { 3-dimensional thickening } \\
\text { of the root walls }\end{array}$ & $\begin{array}{c}\text { Volumetric } \\
\text { change* }\left(\mathbf{m m}^{3}\right)\end{array}$ & $\begin{array}{c}\text { Increase in root } \\
\text { length* }(\mathbf{m m})\end{array}$ & $\begin{array}{c}\text { Pattern of hard tissue deposition } \\
\text { on root canal walls }\end{array}$ \\
\hline 1 & Yes & +19.9 & +1.4 & $\begin{array}{c}\text { On apical 1/3, on buccal and palatal walls, } \\
\text { apex formation } \\
\text { On apical and middle 1/3, random deposition, } \\
\text { apical blunting }\end{array}$ \\
2 & Yes & +21.8 & +0.8 & $\begin{array}{c}\text { Root canal obliteration from apex till middle } \\
1 / 3 \text {, apex formation } \\
\text { On apical 1/3, on buccal and palatal walls, } \\
\text { apical blunting } \\
\text { On apical 1/3, on buccal and palatal walls, } \\
\text { apex formation }\end{array}$ \\
\hline
\end{tabular}

*Measured from the cementoenamel junction.

RET in stimulating hard tissue formation and root maturation. 3D root canal reconstructions showed progressive root canal calcification (obliteration) mostly in the apical part when compared with the contralateral teeth. This finding has been reported in previous studies on RET outcome $(6,7)$; root canal obliteration is a common finding after traumatic dental injures and a desired outcome after autotransplantation of teeth acting as a sign of pulp revitalization $(3-5,27)$. Moreover, visualization of the pattern of hard tissue formation using color-coded maps for root dentin thickness before and after treatment clearly showed the nonuniform nature of hard tissue formation on root canal walls, which was unique for each tooth included in this case report. So far, the significance of the pattern of hard tissue formation is unknown. Future studies including a larger sample size or a multicenter study could implement the method described in the current study to evaluate the relation between baseline situation and the pattern of hard tissue deposition, thus exploring the determinants of success.

The segmentation strategy applied in the current report seems to offer the advantages of increasing accuracy and reducing working time. Using the livewire boundary technique, boundaries are extracted in one fifth of the time required for manual tracing but with 4.4 times greater accuracy and 4.8 times greater reproducibility (22). This proved to be of great value, especially for teeth in the posterior area of the mandible where segmentation is more difficult because of the cortical bone (17). Furthermore, using 3D semiautomatic active contour level set methods available in ITK-SNAP offers the advantages of a greatly reduced working time, high accuracy, and real-time interaction with the segmentation process in contrast to the commonly used low-level methods (region growing). Level set methods offer the possibility of adjusting the contour behavior, making it more suitable for segmenting areas with constrictions around the tooth apex.

This case series described the outcome of 4 patients who presented with 5 immature teeth with periapical infection and pulp necrosis. The RET outcome was in harmony with reported cases in the literature, showing resolution of periapical lesions, bone healing, hard tissue formation of the root canal walls, and root maturation $(6-9,12,28)$. The treatment applied a biantibiotic mix instead of the commonly used triantibiotic mix to reduce the potential risk of discoloration because of the presence of minocycline in the triantibiotic mix (29). Furthermore, EDTA $17 \%$ was used in root canal conditioning after $\mathrm{NaOCl}$ irrigation and directly before the induction of bleeding into the canal to remove the smear layer, expose dentinal tubules and collagen fibrils, and release growth factors from the dentin matrix (21). EDTA is thought to enhance the outcome of RET through optimizing the conditions for cellular differentiation, tissue formation, and regeneration (21).

The aim of this study was to report the outcome of RET using 3D CBCT data and to analyze the outcome in a quantitative method. CBCT images overcome the limitations of 2D images including the lack of the buccolingual dimension, masking of areas of interest by overlying anatomy (anatomic noise), and avoiding geometric distortion. A high spatial resolution and true volumetric information can be obtained because of the isotropic nature of CBCT images $(16,30)$. Moreover, it has been shown that dental trauma and developmental anomalies can be better assessed in 3 dimensions (16, 30-32). Nevertheless, CBCT imaging has its own limitation; the effective radiation dose delivered by CBCT devices available in the market varies enormously from around 10$1200 \mu \mathrm{Sv}$ (which is an equivalent of 2-240 panoramic radiographs) $(33,34)$. Therefore, a proper balance (optimization) between, on the one hand, costs and radiation dose and, on the other hand, information required needs to be maintained (16). Furthermore, the scanned area should not exceed the area of interest. This will limit the dose substantially, thus justifying its use (16, 31, 32). More research is still needed to validate the benefit of applying CBCT imaging in routine monitoring of RET cases.

Quantitative methods using 2D data were successfully reported and validated $(12,35)$. However, working with $2 \mathrm{D}$ data has its limitations such as image standardization and the lack of volumetric measurements. Moreover, 2D imaging does not account for the presence of intracanal calcifications, which is a common finding in cases treated with RET (35). Nevertheless, a standard quantitative method is highly needed to compare results from different studies and to be applied in multicenter prospective studies. Three-dimensional images offer the unique possibility of analyzing the pattern and position of hard tissue formation. The use of standardized 2D data from shortterm monitoring combined with 3D data from long-term monitoring in a study with a large sample size might offer much needed information regarding the outcome of regenerative endodontic procedures. Finally, future research including a larger sample size and control group and comparison with the available 2D methods is needed to validate the clinical application of the method proposed in the current study.

\section{Conclusion}

Analysis of 3D data for teeth treated with regenerative endodontic procedures offers valuable insights into the treatment outcome and patterns of hard tissue formation.

\section{Acknowledgments}

The authors deny any conflicts of interest related to this study.

\section{References}

1. Sfeir C, Onishi S, Yoshizawa S, et al. Introduction to regenerative dentistry. In: Marei M, ed. Regenerative Dentistry. San Rafael, CA: Morgan \& Claypool; 2010:1-17. 


\section{Clinical Research}

2. Murray PE, Garcia-Godoy F, Hargreaves KM. Regenerative endodontics: a review of current status and a call for action. J Endod 2007:33:377-90.

3. Andersson L, Andreasen JO, Day P, et al. International Association of Dental Traumatology guidelines for the management of traumatic dental injuries: 2. Avulsion of permanent teeth. Dent Traumatol 2012;28:88-96.

4. Cvek M, Cleaton-Jones P, Austin J, et al. Pulp revascularization in reimplanted immature monkey incisors - predictability and the effect of antibiotic systemic prophylaxis. Endod Dent Traumatol 1990;6:157-69.

5. Tsukiboshi M. Autotransplantation of teeth: requirements for predictable success Dent Traumatol 2002;18:157-80.

6. Chen MY, Chen KL, Chen CA, et al. Responses of immature permanent teeth with infected necrotic pulp tissue and apical periodontitis/abscess to revascularization procedures. Int Endod J 2012;45:294-305.

7. Chueh LH, Ho YC, Kuo TC, et al. Regenerative endodontic treatment for necrotic immature permanent teeth. J Endod 2009;35:160-4.

8. Hargreaves KM, Geisler T, Henry M, et al. Regeneration potential of the young permanent tooth: what does the future hold? Pediatr Dent 2008;30:253-60.

9. Torabinejad M, Turman M. Revitalization of tooth with necrotic pulp and open apex by using platelet-rich plasma: a case report. J Endod 2011;37:265-8.

10. Pramila R, Muthu MS. Regeneration potential of pulp-dentin complex: systematic review. J Conserv Dent 2012;15:97-103.

11. Reynolds K, Johnson JD, Cohenca N. Pulp revascularization of necrotic bilateral bicuspids using a modified novel technique to eliminate potential coronal discolouration: a case report. Int Endod J 2009;42:84-92.

12. Bose R, Nummikoski $P$, Hargreaves $K$. A retrospective evaluation of radiographic outcomes in immature teeth with necrotic root canal systems treated with regenerative endodontic procedures. J Endod 2009;35:1343-9.

13. Esposito SA, Huybrechts B, Slagmolen P, et al. A novel method to estimate the volume of bone defects using cone-beam computed tomography: an in vitro study. J Endod 2013;39:1111-5.

14. Shahbazian M, Jacobs R, Wyatt J, et al. Validation of the cone beam computed tomography-based stereolithographic surgical guide aiding autotransplantation of teeth: clinical case-control study. Oral Surg Oral Med Oral Pathol Oral Radiol 2013;115:667-75.

15. Yang F, Jacobs R, Willems G. Dental age estimation through volume matching of teeth imaged by cone-beam CT. Forensic Sci Int 2006;159(suppl 1):S78-83.

16. Jacobs R. Dental cone beam CT and its justified use in oral health care. JBR-BTR 2011;94:254-65.

17. Liu Y, Olszewski R, Alexandroni ES, et al. The validity of in vivo tooth volume determinations from cone-beam computed tomography. Angle Orthod 2010;80:160-6.

18. Maret D, Molinier F, Braga J, et al. Accuracy of 3D reconstructions based on cone beam computed tomography. J Dent Res 2010;89:1465-9.
19. Michetti J, Maret D, Mallet JP, et al. Validation of cone beam computed tomography as a tool to explore root canal anatomy. J Endod 2010;36:1187-90.

20. Shahbazian M, Jacobs R, Wyatt J, et al. Accuracy and surgical feasibility of a CBCTbased stereolithographic surgical guide aiding autotransplantation of teeth: in vitro validation. J Oral Rehabil 2010;37:854-9.

21. Galler KM, D'Souza RN, Federlin M, et al. Dentin conditioning codetermines cell fate in regenerative endodontics. J Endod 2011;37:1536-41.

22. Barrett WA, Mortensen EN. Interactive live-wire boundary extraction. Med Image Anal 1997;1:331-41.

23. Suetens P. Medical Image Analysis. Fundamentals of Medical Imaging, 2nd ed. New York: Cambridge University Press; 2009:160-89.

24. Yushkevich PA, Piven J, Hazlett HC, et al. User-guided 3D active contour segmentation of anatomical structures: significantly improved efficiency and reliability. Neuroimage 2006;31:1116-28.

25. Gao Y, Peters OA, Wu H, et al. An application framework of three-dimensional reconstruction and measurement for endodontic research. J Endod 2009;35: 269-74.

26. Bland JM, Altman DG. Statistical methods for assessing agreement between two methods of clinical measurement. Lancet 1986;1:307-10.

27. Tsukiboshi M. Autogenous tooth transplantation: a reevaluation. Int J Periodontics Restorative Dent 1993;13:120-49.

28. Torabinejad M, Faras H. A clinical and histological report of a tooth with an open apex treated with regenerative endodontics using platelet-rich plasma. J Endod 2012;38:864-8.

29. Krastl G, Allgayer N, Lenherr P, et al. Tooth discoloration induced by endodontic materials: a literature review. Dent Traumatol 2013;29:2-7.

30. Patel S. New dimensions in endodontic imaging: part 2. Cone beam computed tomography. Int Endod J 2009;42:463-75.

31. Bornstein MM, Wolner-Hanssen AB, Sendi P, et al. Comparison of intraoral radiography and limited cone beam computed tomography for the assessment of rootfractured permanent teeth. Dent Traumatol 2009;25:571-7.

32. May JJ, Cohenca N, Peters OA. Contemporary management of horizontal root fractures to the permanent dentition: diagnosis-radiologic assessment to include conebeam computed tomography. J Endod 2013;39(suppl):S20-5.

33. Loubele M, Bogaerts R, Van Dijck E, et al. Comparison between effective radiation dose of CBCT and MSCT scanners for dentomaxillofacial applications. Eur J Radiol 2009; $71: 461-8$.

34. Pauwels R, Beinsberger J, Collaert B, et al. Effective dose range for dental cone beam computed tomography scanners. Eur J Radiol 2012;81:267-71.

35. Flake NM, Gibbs JL, Diogenes A, et al. A standardized novel method to measure radiographic root changes after endodontic therapy in immature teeth. J Endod 2014;40:46-50. 